\title{
Postoperative headache after surgical treatment of cerebellopontine angle tumors: a systematic review
}

\author{
Louis Pogoda ${ }^{1}$ (D . Jelle S. Nijdam ${ }^{1}$ • Diederik P. J. Smeeing ${ }^{2} \cdot$ Eduard H. J. Voormolen $^{3} \cdot$ Fuat Ziylan $^{4}$. \\ Hans G. X. M. Thomeer ${ }^{1,5}$
}

Received: 12 November 2020 / Accepted: 16 January 2021 / Published online: 1 February 2021

(c) The Author(s) 2021

\begin{abstract}
Purpose Postoperative headache (POH) is a complication that occurs after surgical resection of cerebellopontine angle (CPA) tumors. The two most common surgical approaches are the translabyrinthine (TL), and retrosigmoid (RS) approach. The objective of this systematic review was to investigate whether POH occurs more frequently after RS compared to TL approaches.

Methods A systematic search was conducted in Cochrane, Pubmed and Embase. Studies were included if POH after CPA tumor removal was reported and both surgical approaches were compared. The methodological quality of the studies was assessed using the Risk Of Bias In Non-randomized Studies of Interventions (ROBINS-I) tool.

Results In total, 3,942 unique articles were screened by title and abstract. After the initial screening process 63 articles were screened for relevance to the inquiry, of which seven studies were included. Three studies found no significant difference between both surgical approaches ( $p=0.871, p=0.120, p=0.592$ ). Three other studies found a lower rate of POH in the TL group compared to the RS group $(p=0.019, p<0.001, p<0.001)$. Another study showed a significantly lower POH rate in the TL group after one and six months $(p=0.006)$, but not after 1 year $(p=0.6)$.

Conclusion The results of this systematic review show some evidence of a lower rate of POH in favor of the TL approach versus the RS approach for CPA tumor resection. Prospective research studies are needed to further investigate this finding.
\end{abstract}

Keywords Cerebellopontine angle tumors · Vestibular schwannoma - Postoperative headache $\cdot$ Translabyrinthine approach . Retrosigmoid approach $\cdot$ Surgical techniques

Hans G. X. M. Thomeer

H.G.X.M.Thomeer@umcutrecht.nl

1 Department of Otorhinolaryngology-Head and Neck Surgery, University Medical Center Utrecht, Utrecht University, Heidelberglaan 100, 3584 CX Utrecht, The Netherlands

2 Department of Surgery, University Medical Center Utrecht, Utrecht University, Utrecht, The Netherlands

3 Department of Neurosurgery, University Medical Center Utrecht, Utrecht University, Utrecht, The Netherlands

4 Department of Otorhinolaryngology-Head and Neck Surgery, Amsterdam Public Health Research Institute, Amsterdam University Medical Center, Vrije Universiteit Amsterdam, Amsterdam, The Netherlands

5 Brain Center Rudolf Magnus, University Medical Center Utrecht, Utrecht University, Utrecht, The Netherlands

\section{Introduction}

Cerebellopontine angle (CPA) tumors account for around $10 \%$ of all intracranial neoplasms [1]. In approximately $98 \%$ of the cases, tumors of the CPA are either vestibular schwannomas (80 to $95 \%$ ) or meningiomas (5 to $15 \%$ ) [2, $3]$. Despite their non-malignant nature, these tumors might induce severe comorbidity and a range of symptoms (i.e. instability and vestibular problems, cranial nerve neuropathy, intracranial hyperpressure, sensorineural hearing loss, tinnitus and headache). Treatment options of CPA tumors encompass observation (wait and scan), radiotherapy or a surgical approach.

The operative management of CPA tumors consists mainly of two different surgical approaches: the translabyrinthine (TL), and retrosigmoid (RS) approach [2, 4]. Both of these techniques are employed for any size of tumor, though only the RS approach can be used in cases 
of hearing preservation surgery. In the minority of cases a third technique, the middle cranial fossa (MF) approach, might be employed in cases of tumors limited to the internal auditory canal (IAC) (or with a minimal CPA extension), with serviceable hearing [5-9]. A disadvantage of the RS approach is that cerebellar retraction is often required to provide enough surgical exposure. Disadvantage of the TL approach is that it leads to total deafness. Despite the advantages and disadvantages of each approach, the main goal of surgical treatment, a (near-total) resection of the tumor with maximum preservation of facial nerve function, could be strived for with all three methods $[2,4,9,10]$.

Postoperative headache $(\mathrm{POH})$ is a known adverse event after CPA surgery, with a significant impact on quality of life [11]. Besides the burden for the individual, chronic pain has a great economic impact $[12,13]$. In approximately $65 \%$ of patients with $\mathrm{POH}$, it lasts beyond the initial postoperative period [4]. Although $84 \%$ of POHs resolve within the first 12 months after surgery, approximately $16 \%$ of patients still present with invalidating (refractory) pain even one year after surgery [14]. The reported rates of $\mathrm{POH}$ vary greatly between the different approaches (TL: 0 to $84 \%$, RS: 10 to 93\%), which might be due to heterogeneity between study populations and differences in POH definitions and study methodology [9, 14-21]. Two systematic reviews identified a trend of less POHs within the group of patients who underwent the TL approach $[9,21]$. However, the results of these reviews were mainly based on single arm studies which were highly heterogeneous and difficult to compare. The goal of this review was to investigate the difference in $\mathrm{POH}$ rates after the two most applied surgical techniques (TL versus RS) of CPA tumor resection.

\section{Materials and methods}

The review was performed in accordance with the Preferred Reporting Items for Systematic Reviews and Meta-Analyses (PRISMA) statement [22, 23].

\section{Search strategy}

In this systematic review an electronic search was performed using the Cochrane, PubMed and EMBASE databases on 19/10/2020. Keywords used for the search included various synonyms and types for the surgical approach and for CPA tumors. The search strings can be found in the Appendix table.

\section{Selection criteria}

Titles and abstracts were screened independently by two authors. After title and abstract screening, potentially valuable articles were read in full text. Articles were included if written in English, Dutch, German, French, Spanish or Turkish language. Comparative studies were included if postoperative headache after CPA tumor removal was reported for both TL and RS approach. Studies were excluded if only one surgical approach was studied, if it concerned animal studies, opinion papers, poster presentations, reviews, meta-analyses, case reports (or less than 10 participants in one of the surgical approach groups), or if no full text was available. Consensus on inclusion and exclusion was reached through discussion between the authors. If no consensus could be reached, a third author was consulted. References and citating articles were screened for additional studies.

\section{Quality assessment}

The methodological quality of the studies was independently assessed by two authors using the risk of bias in non-randomized studies - of interventions (ROBINS-I) tool, to assess the risk of bias in the included studies [24]. Consensus on quality assessment was reached after discussion between the authors.

\section{Data extraction}

Study characteristics and outcome data of the included studies were extracted. Additionally, the following data were extracted: type of surgical approach, type of surgical procedure when undergoing RS tumor resection, number of patients who underwent surgery for CPA tumor, sex, mean age, tumor size, and duration of follow-up.

\section{Statistical analysis}

For calculation of $p$-values, the chi-square test was used.

\section{Results}

\section{Search results and selection process}

A flowchart with the performed selection process is shown in Fig. 1. We retrieved a total of 3,942 articles after removing duplicates. After title and abstract screening, 63 articles were assessed for eligibility in full text. In total, seven studies were deemed eligible and critically appraised: six retrospective cohort studies and one cross-sectional observational study [25-31]. Reviewing of references and citation tracking did not result in additional relevant articles. 


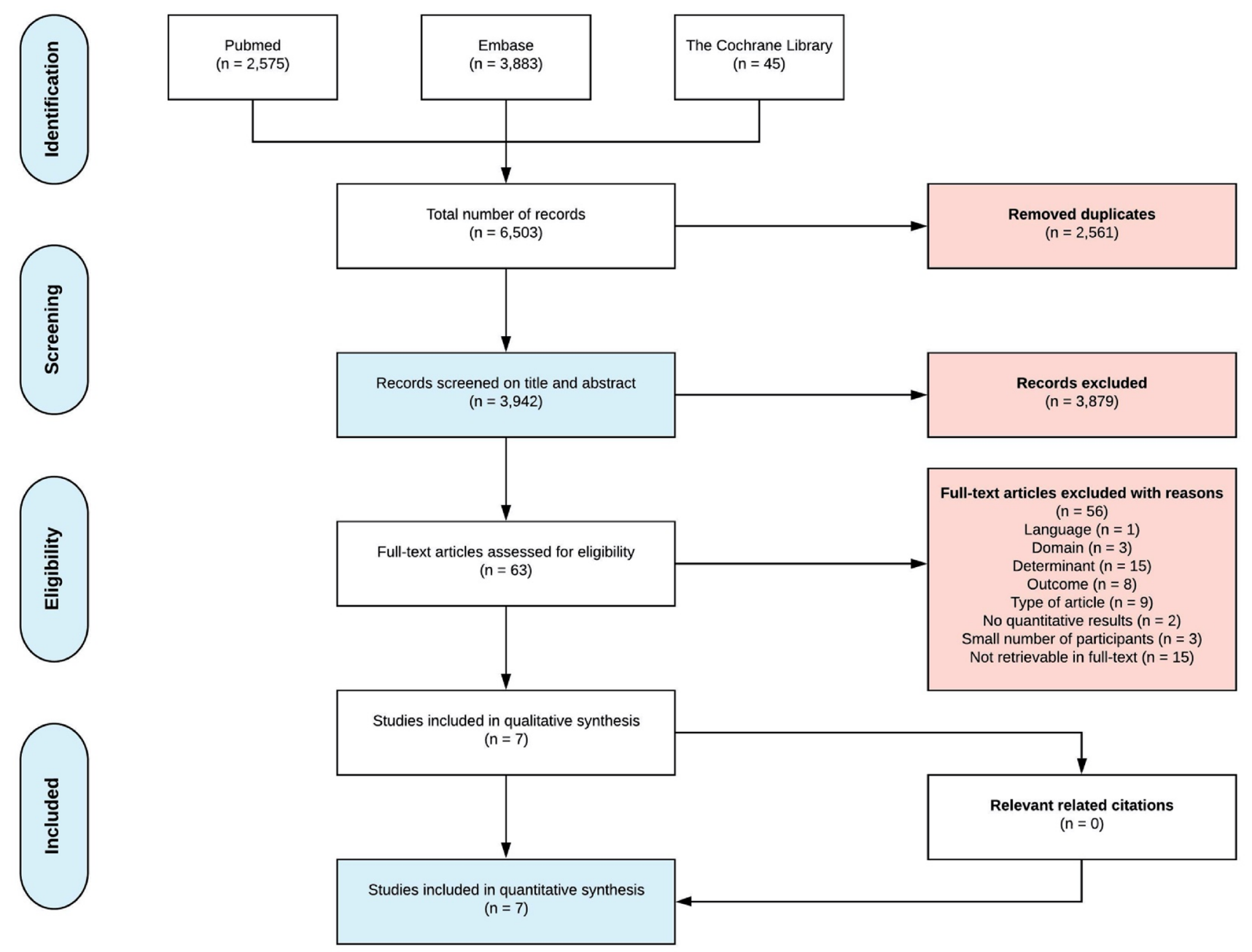

Fig. 1 Flowchart of inclusion of relevant publications

\section{Quality assessment}

The results of the critical appraisal are shown in Table 1. Overall, one study scored a moderate risk of bias, and six studies scored a serious risk of bias.

\section{Baseline characteristics of included studies}

The baseline characteristics of the included studies are shown in Table 2. All studies are similar regarding in- and exclusion criteria with the exception of Ryzenman et al. and Schessel et al., who included children and did not quantify the exact number of patients in this group [27, 31].

In total, the results of 2,161 patients were included. The TL approach was performed in 1,076 patients whereas 1,085 patients underwent the RS approach. All patients suffered from unilateral CPA tumors and the majority of participants were female $(61.4 \%)$. The patient mean age was 53 years (range 13 to 90 ). Three studies provided the exact proportion of patients who underwent craniectomy or cranioplasty when undergoing CPA tumor surgery through the RS approach [25, 30, 31]. Of the 228 participants undergoing the RS approach in these studies, 152 underwent cranioplasty with autologous bone graft and 76 craniectomy. Levo et al. used the RS approach for larger CPA tumors, whereas Ruckenstein et al. and Schessel et al. used the TL approach for larger tumors [26, 30, 31]. The duration of follow-up of the included studies varied from 1 month to 14 years [25-31].

\section{Postoperative headache rates after TL versus $\mathrm{RS}$ approach}

The outcomes of the included studies are presented in Table 3. In total, $23.4 \%$ (494 out of 2,108) of the patients experienced POH, $36.2 \%$ (380 out of 1,050) of the RS group and $10.8 \%$ (114 out of 1058) of the TL group. Three studies, by Levo et al., Ryzenman et al. and Schessel et al., reported a significantly lower prevalence of chronic $\mathrm{POH}$ in the TL 
Table 1 Critical appraisal

\begin{tabular}{|c|c|c|c|c|c|c|c|c|}
\hline Article & Confounding & $\begin{array}{l}\text { Selection of } \\
\text { participants }\end{array}$ & $\begin{array}{l}\text { Classification } \\
\text { of interven- } \\
\text { tions }\end{array}$ & $\begin{array}{l}\text { Deviations } \\
\text { from intended } \\
\text { interventions }\end{array}$ & Missing data & $\begin{array}{l}\text { Measurement } \\
\text { of outcomes }\end{array}$ & $\begin{array}{l}\text { Selection of the } \\
\text { reported results }\end{array}$ & $\begin{array}{l}\text { Overall risk of } \\
\text { bias }\end{array}$ \\
\hline Carlson 2015 & $\mathrm{~L}$ & S & $\mathrm{L}$ & $\mathrm{L}$ & NI & M & $\mathrm{L}$ & Serious \\
\hline $\begin{array}{l}\text { Levo } \\
2000\end{array}$ & $\mathrm{~L}$ & S & $\mathrm{L}$ & $\mathrm{L}$ & $\mathrm{L}$ & M & $\mathrm{L}$ & Serious \\
\hline $\begin{array}{l}\text { Pedrosa } \\
1994\end{array}$ & $\mathrm{~L}$ & S & $\mathrm{L}$ & $\mathrm{L}$ & $\mathrm{NI}$ & M & $\mathrm{L}$ & Serious \\
\hline $\begin{array}{l}\text { Rameh } \\
2010\end{array}$ & $\mathrm{~L}$ & S & $\mathrm{L}$ & $\mathrm{L}$ & NI & M & $\mathrm{L}$ & Serious \\
\hline $\begin{array}{l}\text { Ruckenstein } \\
1996\end{array}$ & $\mathrm{~L}$ & $\mathrm{~L}$ & $\mathrm{~L}$ & $\mathrm{~L}$ & NI & M & $\mathrm{L}$ & Moderate \\
\hline $\begin{array}{l}\text { Ryzenmann } \\
2004\end{array}$ & $\mathrm{~L}$ & S & $\mathrm{L}$ & $\mathrm{L}$ & NI & M & $\mathrm{L}$ & Serious \\
\hline $\begin{array}{l}\text { Schessel } \\
1992\end{array}$ & $\mathrm{~L}$ & S & $\mathrm{L}$ & $\mathrm{L}$ & $\mathrm{NI}$ & M & $\mathrm{L}$ & Serious \\
\hline
\end{tabular}

$L$ low risk of bias; $M$ moderate risk of bias; $S$ serious risk of bias; $N I$ no information

group ( $p=0.019, p<0.001$ and $p<0.001$, respectively) $[26,27,31]$. Ruckenstein et al. found a significantly lower $\mathrm{POH}$ rate at one and six months after surgery in patients undergoing the TL approach [30]. One year after surgery, this difference was no longer present. Two other studies, by Pedrosa et al. and Rameh et al., reported that the TL approach was associated with a lower incidence of $\mathrm{POH}$ compared to the RS approach, no significant difference between the two surgical approaches was found ( $p=0.12$ and $p=0.59$, respectively) $[25,28]$. Carlson et al. included 128 patients, of which 94 (73.4\%) in the RS and 34 (26.6\%) in the TL group, and reported a $1.5 \%$ higher $\mathrm{POH}$ rate in patients undergoing the TL approach $(p=0.87)$ [29]. In the study by Pedrosa et al. both retrosigmoid craniectomy and cranioplasty with autologous graft were performed [25]. In the craniectomy group, 15 out of $18(83 \%)$ patients reported headache, in comparison to 83 of the 117 (71\%) patients in the cranioplasty group $(p=0.27)$.

\section{Discussion}

\section{Principal findings}

The objective of our systematic review was to investigate differences in $\mathrm{POH}$ rates between translabyrinthine (TL) and retrosigmoid (RS) approaches for resection of cerebellopontine angle (CPA) tumors. Overall, $23.4 \%$ of the subjects had POH, $36.2 \%$ of the RS group compared to $10.8 \%$ of the TL group. The study by Ruckenstein et al. was not used for this calculation because of insufficient data. We found three studies in which no significant difference between the two approaches was found ( $p=0.871, p=0.120, p=0.592$ ) $[25,28,29]$, and three studies in which a significantly lower rate of $\mathrm{POH}$ was found in the TL group compared to the RS group ( $p=0.019, p<0.001$ and $p<0.001)$ [26, 27, 31]. One study showed a significantly lower $\mathrm{POH}$ rate in the TL group after one and six months, but not after one year [30].

Previously, two reviews investigated the frequency of postoperative complications following CPA tumor resection [9, 21]. Sabab et al. found six studies reporting a trend towards lower $\mathrm{POH}$ rates in patients treated with the TL approach, of which one study presented statistically significant evidence $(p<0.05)$ [9]. The review by Ansari et al., also found a significant difference in chronic $\mathrm{POH}$ rates in favor of the TL approach $(p<0.001)$ [21]. However, this result was based on only one study, and therefore can be biased by coincidence. Furthermore, in both reviews little information was given about the quality and contents of the used studies [9, 21]. Therefore, we solely included comparative studies investigating $\mathrm{POH}$ rates between both the RS and the TL approaches in our systematic review, and critically appraised the scientific quality of the studies. This way, the patient groups had a higher comparability between the two approaches.

Overall, the individual quality of the included articles was poor. Only one study scored a moderate risk of bias [30]. Accordingly, we considered this result to be more reliable, compared to the other six studies, which scored a serious overall risk of bias because no information was available on the exact follow-up time points in the two different surgical approaches [25-29, 31]. Therefore, those results need to be interpreted more carefully.

Another important factor that should be taken into consideration is sample size. Two of the studies that found significant differences between the approaches were the largest studies we included regarding total subject count [26, 27]. The relatively small sample sizes of the remaining studies 


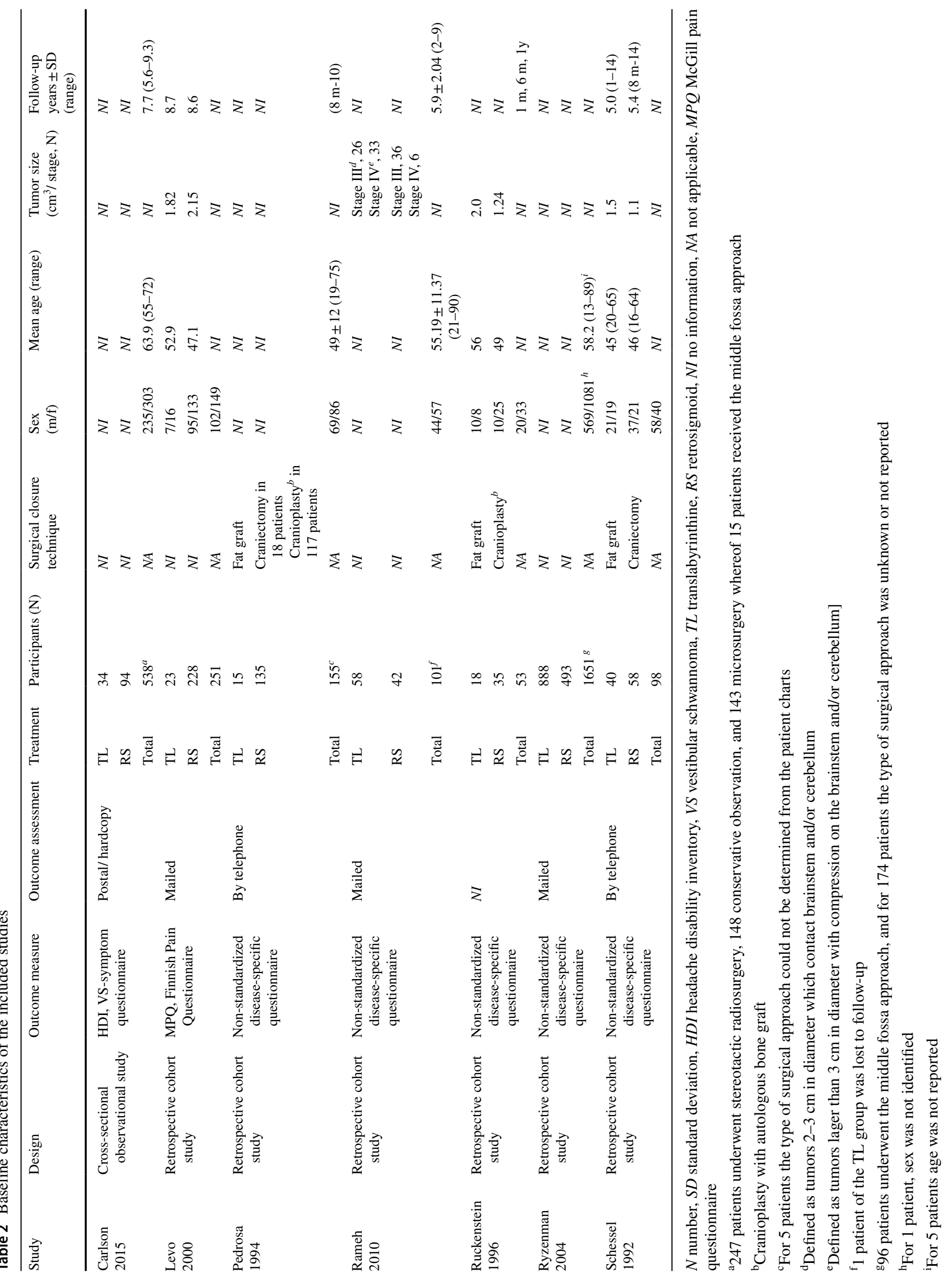


Table 3 Comparison of $\mathrm{POH}$ rates after translabyrinthine versus retrosigmoid approach

\begin{tabular}{|c|c|c|c|c|c|c|c|}
\hline Article & Outcome measure & RS, total $N$ & Outcome yes, $N(\%)$ & TL, total $N$ & Outcome yes, $N(\%)$ & $\begin{array}{l}\text { Difference } \\
\text { (\%TL-\%RS) }\end{array}$ & $p$-value ${ }^{\mathrm{a}}$ \\
\hline $\begin{array}{l}\text { Carlson } \\
2015\end{array}$ & $\mathrm{HDI}>14$ & 94 & $29(30.9)$ & 34 & $11(32.4)$ & $1.5 \%$ & 0.871 \\
\hline $\begin{array}{l}\text { Levo } \\
2000\end{array}$ & Self-reported headache & 228 & $97(42.5)$ & 23 & $4(17.4)$ & $-33.5 \%$ & 0.019 \\
\hline $\begin{array}{l}\text { Pedrosa } \\
1994\end{array}$ & Self-reported headache & 135 & $98(72.6)$ & 15 & $8(53.3)$ & $-19.3 \%$ & 0.120 \\
\hline $\begin{array}{l}\text { Rameh } \\
2010\end{array}$ & Self-reported headache & 42 & $24(57.1)$ & 58 & $30(51.7)$ & $-5.4 \%$ & 0.592 \\
\hline $\begin{array}{l}\text { Ruckenstein } \\
1996\end{array}$ & Self-reported headache & 35 & $N I^{b}$ & 18 & $N I^{b}$ & $N I^{b}$ & $0.03^{c} ; 0.006^{d} ; 0.6^{e}$ \\
\hline $\begin{array}{l}\text { Ryzenmann } \\
2004\end{array}$ & Self-reported headache & 493 & $95(19.3)$ & 888 & $61(6.9)$ & $-12.4 \%$ & $<0.001$ \\
\hline $\begin{array}{l}\text { Schessel } \\
1992\end{array}$ & Self-reported headache & 58 & $37(63.7)$ & 40 & $0(0.0)$ & $-63.7 \%$ & $<0.001$ \\
\hline
\end{tabular}

$P O H$ postoperative headache, $R S$ retrosigmoid, $N$ number, $T L$ translabyrinthine, $H D I$ headache disability inventory, $N I$ no information

${ }^{\mathrm{a}}$ Calculated using chi-square test

${ }^{b}$ No exact numbers given in the article

${ }^{c} p$-value retrieved from the article, after 1 month follow-up

${ }^{\mathrm{d}} p$-value retrieved from the article, after 6 months follow-up

e $p$-value retrieved from the article, after 1 year follow-up

could pose a bias that needs to be considered in the interpretation of the different study outcomes [25, 28-31]. Also, a difference should be noted between the outcome parameters. The study by Carlson et al. used a headache disability inventory (HDI) score $>14$ as outcome measure, while the other studies scored 'headache in general' as outcome measure [29]. The headache disability inventory (HDI) score does not directly reflect the occurrence of headache (but rather the impact of headache on quality of life) which makes the results of the study by Carlson et al. and the other studies hard to compare. Furthermore, the studies we have included and analyzed all reported different durations of follow-up (range 1 months to 14 years). This could influence the results as is seen in the study by Ruckenstein et al., where a different result is found at 1 months and 6 months follow-up compared to 1 year follow-up [30]. However, because we included only seven studies, and data on aforementioned factors is missing in some studies, it is not possible to take these factors into account for this review. Furthermore, the difference in outcome parameters and follow-up durations made the data unsuitable for a meta-analysis.

\section{Hypothetical mechanisms underlying POH after RS versus TL}

We hypothesized that $\mathrm{POH}$ occurs more frequently in patients treated with the RS approach than in those treated with the TL approach. One reason is that drilling into the
IAC during RS tumor resection increases the risk of bone dust entering the posterior fossa causing tissue reactions and, possibly, irritative arachnoiditis [2, 4, 30-34]. Additionally, surgical incisions to the suboccipital musculature (i.e. m. occipitalis and m. trapezius) might consequently lead to ingrowth of these anatomical structures into the exposed dura in the postoperative course $[2,4$, 30-34]. This healing process can result in postoperative adherences, leading to $\mathrm{POH}$ as well. Considering that, the applied surgical details of the reported RS procedure could have an influence on the results regarding $\mathrm{POH}$. Several studies have reported lower rates of $\mathrm{POH}$ in subjects undergoing cranioplasty, rather than craniectomy [9, 25]. More precisely, bone replacement instead of solely removing it may reduce the occurrence of tissue reactions and postoperative adherences between musculature and dura which results in lower $\mathrm{POH}$ rates. In the TL procedure there is no such dural exposure to ingrowing musculature, nor is intradural drilling applied during the procedure. These are two interesting differences in surgical details which might have an influence on the outcome. Therefore, future clinical prospective studies with precise followup will be necessary to further confirm our hypothesis. They should distinguish carefully between the performance of cranioplasty and craniectomy, as this might be the confounding factor that makes the RS approach with only craniectomy more prone to the occurrence of $\mathrm{POH}$. Moreover, it would be interesting to directly compare the 
occurrence rate of $\mathrm{POH}$ between the RS approach with only cranioplasty and the TL approach.

\section{Clinical and surgical implications and future perspectives}

Studies on this subject are limited, and consist frequently of small sample sizes or have a serious risk of bias. Thus, for clinical practice we cannot make recommendations based on this review.

However, the two largest studies in this review show a significantly lower rate of $\mathrm{POH}$ when using the TL approach, compared to the RS approach [26, 27]. The study by Ruckenstein et al. has a relatively small sample size, but a moderate risk of bias, and shows significantly lower rates of $\mathrm{POH}$ at two of the three measured time points in favor of the TL approach. Furthermore, the differences in $\mathrm{POH}$ rates in the aforementioned studies are relatively large. This, combined with the burden of chronic headache, make the possible difference in $\mathrm{POH}$ rates between the two approaches clinically relevant. We believe that this is enough reason for further prospective research, with proper methodology to ascertain if this is an existing phenomenon and parameter the surgical team should take into account. And if so, how large the difference in $\mathrm{POH}$ rates is. We performed a sample size calculation for a significance level of $95 \%$ and a power of $80 \%$ for different expected $\mathrm{POH}$ rates, based on our current results (Table 4).

\section{Strengths and limitations}

The main strengths of our study are the systematic approach and our comprehensive search strategy, which allowed us to identify all relevant articles and available data from the literature. The main limitation is that we had to exclude 15 possibly relevant studies, because there were no full texts available even after consulting a scientific librarian. Also the retrospective character of the included studies and mostly unfixed postoperative follow-up periods are important setbacks.
Table 4 Sample size calculation

\begin{tabular}{llll}
\hline Ratio N of subjects RS:TL & 2 & 1 & 0.5 \\
\hline $\begin{array}{l}\text { Levo } \\
43 \% \text { POH in RS }\end{array}$ & 128 & 112 & 120 \\
$17 \%$ POH in TL & & & \\
Ryzenmann & 324 & 276 & 297 \\
$19 \%$ POH in RS & & & \\
$7 \%$ POH in TL & & & \\
Average $^{a}$ & 215 & 188 & 209 \\
$48 \%$ POH in RS & & & \\
$27 \%$ POH in TL & & & \\
Total & & & \\
$36 \%$ POH in RS & 119 & 102 & \\
$11 \%$ POH in TL & & & \\
\hline
\end{tabular}

Sample size calculation based on an $\alpha$ of 0.05 and a power of $80 \%$ ( $\beta=0.2$ ) using Fleiss' method with continuity correction [35]. In the rows, the expected values of headache rates for both surgical methods are given, based on the results of the two largest studies included in this review, and on the average and total postoperative headache rates calculated using six of the seven included studies (Ruckenstein 1996 excluded because of insufficient information). In the columns the ratio of the number of subjects in the RS and in the TL group are given. The displayed sample sizes are the total numbers of participants needed, given the expected postoperative headache rates and the ratio of subjects in the RS and the TL groups

$N$ number, $R S$ retrosigmoid, $T L$ translabyrinthine, $P O H$ postoperative headachel

${ }^{a}$ Average rates of $\mathrm{POH}$ calculated using six of the seven included studies (Ruckenstein 1996 excluded because of insufficient information)

${ }^{\mathrm{b}}$ Rates of POH calculated using the total numbers of participants in six of the seven included studies (Ruckenstein 1996 excluded because of insufficient information)

\section{Conclusion and Recommendation}

In conclusion, the results of this systematic review show some evidence of a lower rate of chronic postoperative headache when using the translabyrinthine approach over the retrosigmoid approach for benign CPA tumor surgery. Further prospective research is advocated to elucidate this important topic.

\section{Appendix}

See Table 5. 
Table 5 The performed search on Cochrane, PubMed and EMBASE (19-10-2020)

\begin{tabular}{|c|c|c|}
\hline Database & Terms & Hits \\
\hline Pubmed & $\begin{array}{l}\text { (((Vestibular[Title/Abstract] OR Acoustic[Title/Abstract] OR Cerebellopontine[Title/Abstract] OR } \\
\text { Cerebellopontine[Title/Abstract])) AND (Schwannoma*[Title/Abstract] OR Neuroma*[Title/Abstract] OR } \\
\text { Neurinoma*[Title/Abstract] OR Neurilemoma*[Title/Abstract] OR meningioma*[Title/Abstract] OR tumor*[Title/ } \\
\text { Abstract])) OR (neuroma, acoustic[MeSH Terms] OR meningioma[MeSH Terms]) AND ((Retrosigmoid[Title/ } \\
\text { Abstract] OR RS[Title/Abstract] OR Translabyrinthine[Title/Abstract] OR TL[Title/Abstract] OR Suboccipital[Title/ } \\
\text { Abstract]) OR (headache [Title/Abstract])) }\end{array}$ & 2,575 \\
\hline Embase & 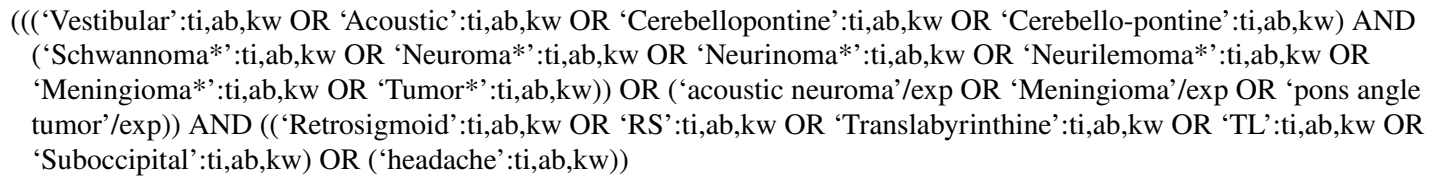 & 3,883 \\
\hline Cochrane & $\begin{array}{l}\text { ((Vestibular OR Acoustic OR Cerebellopontine OR Cerebellopontine) AND (Schwannoma* OR Neuroma* OR Neuri- } \\
\text { noma* OR Neurilemoma* OR meningioma* OR tumor*)) OR Neuroma, acoustic OR Meningioma AND ((Retrosig- } \\
\text { moid OR RS OR Translabyrinthine OR TL OR Suboccipital) OR (headache)) }\end{array}$ & 45 \\
\hline \multicolumn{3}{|c|}{ Total number of articles found $=6,503$} \\
\hline \multicolumn{3}{|c|}{ Number of articles after deduplication $=3,942$} \\
\hline
\end{tabular}

Funding The authors indicate that they have no financial disclosure.

\section{Compliance with ethical standards}

Conflict of interest The authors declare that they have no conflict of interest.

Open Access This article is licensed under a Creative Commons Attribution 4.0 International License, which permits use, sharing, adaptation, distribution and reproduction in any medium or format, as long as you give appropriate credit to the original author(s) and the source, provide a link to the Creative Commons licence, and indicate if changes were made. The images or other third party material in this article are included in the article's Creative Commons licence, unless indicated otherwise in a credit line to the material. If material is not included in the article's Creative Commons licence and your intended use is not permitted by statutory regulation or exceeds the permitted use, you will need to obtain permission directly from the copyright holder. To view a copy of this licence, visit http://creativecommons.org/licenses/by/4.0/.

\section{References}

1. Canbaz N, Atılgan E, Tarakcı E, Papaker MG (2019) Evaluation of balance after surgery for cerebellopontine angle tumor. J Back Musculoskelet Rehabil 32(1):93-99. https://doi.org/10.3233/ BMR-181198

2. Betka J, Zvěřina $E$, Balogová $Z$ et al (2014) Complications of microsurgery of vestibular schwannoma. Biomed Res Int 2014:315952. https://doi.org/10.1155/2014/315952

3. Venkatasamy A, Le Foll D, Karol A et al (2017) Differentiation of vestibular schwannomas from meningiomas of the internal auditory canal using perilymphatic signal evaluation on T2-weighted gradient-echo fast imaging employing steady state acquisition at 3T. Eur Radiol Exp 1(1):8. https://doi.org/10.1186/s4174 7-017-0012-7
4. Bennett M, Haynes DS (2007) Surgical approaches and complications in the removal of vestibular schwannomas. Otolaryngol Clin North Am 40(3):589-609. https://doi.org/10.1016/j. otc.2007.03.007

5. Woodson EA, Dempewolf RD, Gubbels SP et al (2010) Longterm hearing preservation after microsurgical excision of vestibular schwannoma. Otol Neurotol 31(7):1144-1152. https://doi. org/10.1097/MAO.0b013e3181edb8b2

6. Roche JP, Woodson EA, Hansen MR, Gantz BJ (2018) Ultra long-term audiometric outcomes in the treatment of vestibular schwannoma with the middle cranial fossa approach. Otol Neurotol 39(2):e151-e157. https://doi.org/10.1097/MAO.0000000000 001678

7. Meyer TA, Canty PA, Wilkinson EP, Hansen MR, Rubinstein JT, Gantz BJ (2006) Small acoustic neuromas: surgical outcomes versus observation or radiation. Otol Neurotol 27(3):380-392. https ://doi.org/10.1097/00129492-200604000-00015

8. Garcia-Ibanez E, Garcia-Ibanez JL (1980) Middle fossa vestibular neurectomy: a report of 373 cases. Otolaryngol Head Neck Surg 88(4):486-490

9. Sabab A, Sandhu J, Bacchi S, Jukes A, Zacest A (2018) Postoperative headache following treatment of vestibular schwannoma: a literature review. J Clin Neurosci 52:26-31. https://doi. org/10.1016/j.jocn.2018.04.003

10. Rahimpour S, Friedman AH, Fukushima T, Zomorodi AR (2016) Microsurgical resection of vestibular schwannomas: complication avoidance. J Neurooncol 130(2):367-375. https://doi.org/10.1007/ s11060-016-2260-4

11. Santa Maria C, Santa Maria PL, Bulsara V et al (2019) Long-term quality of life in patients with vestibular schwannoma managed with microsurgery. J Laryngol Otol. https://doi.org/10.1017/S0022 215119002172

12. Andrew R, Derry S, Taylor RS, Straube S, Phillips CJ (2014) The costs and consequences of adequately managed chronic noncancer pain and chronic neuropathic pain. Pain Pract 14(1):79-94. https://doi.org/10.1111/papr.12050

13. Azevedo LF, Costa-Pereira A, Mendonça L, Dias CC, CastroLopes JM (2016) The economic impact of chronic pain: a nationwide population-based cost-of-illness study in Portugal. Eur J Health Econ 17(1):87-98. https://doi.org/10.1007/s1019 8-014-0659-4 
14. Harner SG, Beatty CW, Ebersold MJ (1993) Headache after acoustic neuroma excision. Am J Otol 14(6):552-555

15. Schessel DA, Rowed DW, Nedzelski JM, Feghali JG (1993) Postoperative pain following excision of acoustic neuroma by the suboccipital approach: observations on possible cause and potential amelioration. Am J Otol 14(5):491-494. https://doi. org/10.1097/00129492-199309000-00014

16. Somers T, Offeciers FE, Schatteman I (2003) Results of 100 vestibular schwannoma operations. Acta Otorhinolaryngol Belg 57(2):155-166

17. Wazen JJ, Sisti M, Lam SM (2000) Cranioplasty in acoustic neuroma surgery. Laryngoscope 110(8):1294-1297. https://doi. org/10.1097/00005537-200008000-00013

18. Harner SG, Beatty CW, Ebersold MJ (1995) Impact of cranioplasty on headache after acoustic neuroma removal. Neurosurgery 36(6):1097-1100. https://doi.org/10.1227/00006123199506000-00005

19. Staecker H, Nadol JB Jr, Ojeman R, Ronner S, McKenna MJ (2000) Hearing preservation in acoustic neuroma surgery: middle fossa versus retrosigmoid approach. Am J Otol 21(3):399 404. https://doi.org/10.1016/s0196-0709(00)80051-4

20. Ryzenman JM, Pensak ML, Tew JM Jr (2005) Headache: a quality of life analysis in a cohort of 1,657 patients undergoing acoustic neuroma surgery, results from the acoustic neuroma association. Laryngoscope 115(4):703-711. https://doi. org/10.1097/01.mlg.0000161331.83224.c5

21. Ansari SF, Terry C, Cohen-Gadol AA (2012) Surgery for vestibular schwannomas: a systematic review of complications by approach. Neurosurg Focus 33(3):E14. https://doi. org/10.3171/2012.6.FOCUS12163

22. Moher D, Liberati A, Tetzlaff J, Altman DG, PRISMA Group (2009) Preferred reporting items for systematic reviews and meta-analyses: the PRISMA statement. BMJ 339:b2535. https ://doi.org/10.1136/bmj.b2535

23. Liberati A, Altman DG, Tetzlaff J et al (2009) The PRISMA statement for reporting systematic reviews and meta-analyses of studies that evaluate healthcare interventions: explanation and elaboration. BMJ 339:b2700. https://doi.org/10.1136/bmj. b2700

24. Sterne JA, Hernán MA, Reeves BC et al (2016) ROBINS-I: a tool for assessing risk of bias in non-randomised studies of interventions. BMJ 355:i4919. https://doi.org/10.1136/bmj.i4919

25. Pedrosa CA, Ahern DK, McKenna MJ, Ojemann RG, Acquadro MA (1994) Determinants and impact of headache after acoustic neuroma surgery. Am J Otol 15(6):793-797

26. Levo H, Pyykkö I, Blomstedt G (2000) Postoperative headache after surgery for vestibular schwannoma. Ann Otol Rhinol
Laryngol 109(9):853-858. https://doi.org/10.1177/0003489400 10900913

27. Ryzenman JM, Pensak ML, Tew JM Jr (2004) Patient perception of comorbid conditions after acoustic neuroma management: survey results from the acoustic neuroma association. Laryngoscope 114(5):814-820. https://doi.org/10.1097/00005537-20040 5000-00005

28. Rameh C, Magnan J (2010) Quality of life of patients following stages III-IV vestibular schwannoma surgery using the retrosigmoid and translabyrinthine approaches. Auris Nasus Larynx 37(5):546-552. https://doi.org/10.1016/j.anl.2010.01.004

29. Carlson ML, Tveiten $\varnothing \mathrm{V}$, Driscoll CL et al (2015) Risk factors and analysis of long-term headache in sporadic vestibular schwannoma: a multicenter cross-sectional study. J Neurosurg 123(5):1276-1286. https://doi.org/10.3171/2014.12.JNS142109

30. Ruckenstein MJ, Harris JP, Cueva RA, Prioleau G, Alksne J (1996) Pain subsequent to resection of acoustic neuromas via suboccipital and translabyrinthine approaches. Am J Otol 17(4):620-624

31. Schessel DA, Nedzelski JM, Rowed D, Feghali JG (1992) Pain after surgery for acoustic neuroma. Otolaryngol Head Neck Surg 107(3):424-429. https://doi.org/10.1177/019459989210700314

32. Schaller B, Baumann A (2003) Headache after removal of vestibular schwannoma via the retrosigmoid approach: a long-term follow-up-study. Otolaryngol Head Neck Surg 128(3):387-395. https://doi.org/10.1067/mhn.2003.104

33. Darrouzet V, Martel J, Enée V, Bébéar JP, Guérin J (2004) Vestibular schwannoma surgery outcomes: our multidisciplinary experience in 400 cases over 17 years. Laryngoscope 114(4):681-688. https://doi.org/10.1097/00005537-200404000-00016

34. Lorefice E, Marcó Del Pont F, Giovannini SJM, Cavanagh S, Goicochea MT, Cervio A (2020) Postcraniectomy pain: comparison between 2 incisions for the retrosigmoid approach Prospective randomized study. Neurocirugia (Astur) 31(6):261-267. https:// doi.org/10.1016/j.neucir.2020.01.003

35. Fleiss JL, Tytun A, Ury HK (1980) A simple approximation for calculating sample sizes for comparing independent proportions. Biometrics 36(2):343-346

Publisher's Note Springer Nature remains neutral with regard to jurisdictional claims in published maps and institutional affiliations. 